\title{
Propiedades antirradicales libres y antibacterianas de extractos de corteza de pino
}

\author{
Martha Rosales Castro ${ }^{1}$, María Elena Pérez López ${ }^{1}$, \\ María del Carmen Ponce Rodríguez ${ }^{1}$
}

\section{RESUMEN}

\begin{abstract}
Se evaluó la actividad de captura de radicales libres de extractos etanólicos y acuosos de la corteza de Pinus ayacahuite, Pinus cooperi, Pinus durangensis, Pinus leiophylla y Pinus teocote, utilizando el método del radical difenilpicrilhidracilo (DPPH), a concentraciones de extracto de $(250,500$, $750,1000$ y 1250$) \mathrm{mg} \mathrm{L}^{-1}$. La actividad se comparó con la de los antioxidantes comerciales butilhydroxitolueno (BHT) y butilhydroxianisol (BHA). Los extractos etanólicos presentaron mayor actividad que los acuosos, sobresaliendo las especies $P$. leiophylla y $P$. durangensis, con capacidades antirradicales a $500 \mathrm{mg} \mathrm{L}^{-1}$ de $(90,4 \pm 0,98) \%$ y $(83,0 \pm$ a 41$) \%$, similares a BHA $(83,6 \pm 0,20) \%$ y superiores a BHT $(50,3 \pm 0,72)$. A excepción de $P$. cooperi, todos los extractos, tanto etanólicos como acuosos presentaron actividad superior al $90,0 \%$ a $1250 \mathrm{mg} \mathrm{L}^{-1}$. Se calculó la concentración para inhibir el 50,0 \% de los radicales $\left(\mathrm{CE}_{50}\right)$. La actividad antibacteriana se evaluó por el método de dilución en agar, sobre Staphylococcus aureus, Enterococcus sp., Escherichia coli y Pseudomonas aeruginosa a concentraciones de $(0,625,2,5,5,0,10,0$ y 20,0$) \mathrm{mg} / \mathrm{mL}$. Se reportó como la concentración mínima inhibitoria (CMI) para impedir el crecimiento bacteriano. En general los extractos etanólicos mostraron mayor inhibición que los acuosos, $S$. aureus se inhibió eficientemente (смl $0,625 \mathrm{mg} / \mathrm{mL})$, Enterococcus sp., moderadamente (CMI $2,5 \mathrm{mg} / \mathrm{mL}$ ), E. coli no tuvo buena inhibición (CMI 10,0 a 20,0) $\mathrm{mg} / \mathrm{mL}$ y $P$. aeruginosa solo se inhibió eficientemente por el extracto etanólico de $P$. cooperi $(2,5 \mathrm{mg} / \mathrm{mL})$.
\end{abstract}

PALABRAS CLAVE:

Actividad antibacteriana, corteza de pino, DPPH, extractos.

\section{ABSTRACT}

Free radicals scavengers of ethanolic and aqueous extracts from Pinus ayacahuite, Pinus cooperi, Pinus durangensis, Pinus leiophylla and Pinus teocote bark were evaluated, using the diphenylpicrylhydrazyl (DPPH) radical assay, to extract concentrations of $(250,500,750,1000$ and 1250$) \mathrm{mg} \mathrm{L}^{-1}$. The scavengers were compared with butilhydroxitolueno (BHT) and butilhydroxianisol (BHA). Ethanolic extracts had higher activity than the aqueous one, specially $P$. leiophylla and $P$. durangensis, with scavengers at $500 \mathrm{mg} \mathrm{L}^{-1}$ of $(90,4 \pm 0,98) \%$ and $(83,0 \pm 1,41) \%$, similar to BHA $(83,6 \pm 0,20) \%$ and higher than BHT $(50,3 \pm 0,72) \%$. Other than $P$. cooperi all extracts showed scavengers higher to $90,0 \%$ at $1250 \mathrm{mg} \mathrm{L}^{-1}$. The concentration for scavengers $50,0 \%$ of radical $\left(\mathrm{CE}_{50}\right)$ was evaluated. The antimicrobial activity of the extracts was evaluated using agar dilution method against Staphylococcus aureus, Enterococcus sp., Escherichia coli and Pseudomonas aeruginosa to concentrations of $(0,625,2,5,5,0,10,0$ and 20,0) $\mathrm{mg} / \mathrm{mL}$. The minimal inhibitory concentration (MIC) was reported. Ethanolic extracts had higher activity than the aqueous one. S. aureus was the most inhibited (MIC $0,625 \mathrm{mg} / \mathrm{mL}$ ), Enterococcus sp. moderaty inhibited (MIC 2,5 mg/mL), E. coli do not had a good inhibition (MIC 10,0 to 20,0) $\mathrm{mg} / \mathrm{mL}$. P. aeruginosa only was efficiently inhibited by $P$. cooperi $(2,5 \mathrm{mg} / \mathrm{mL})$ ethanolic extract.

KEY WORDS:

Antibacterian activity, Pinus bark, DPPH, extracts.

1 CIIDIR IPN Unidad Durango, Av. Sigma s/n Fracc. 20 de Noviembre II, Durango, Durango. ce: mrosa0563@yahoo.com 


\section{INTRODUCCIÓN}

Se consideran radicales libres aquellas moléculas que en su estructura atómica presentan un electrón desapareado o impar en el orbital externo, dándole una configuración espacial que genera una alta inestabilidad. Son muy reactivos y con una enorme capacidad para combinarse con diversas moléculas que integran la estructura celular, como carbohidratos, lípidos, proteínas, ácidos nucléicos y derivados de ellos (Rodríguez et al., 2001; González et al., 2000).

En el cuerpo humano, los radicales libres se producen de forma continua como un producto del metabolismo normal de cada célula y son inactivados por diversos mecanismos enzimáticos y de captura. Cuando hay ausencia de balance entre la generación de radicales libres y los mecanismos de defensa del organismo, puede ocurrir daño oxidativo en la membrana celular y en los tejidos, y generarse alteraciones funcionales que ocasionan diversas enfermedades. Se ha reportado que una serie de enfermedades como arteroesclerosis, inflamaciones, envejecimiento, diabetes, cáncer, mal de Parkinson y Alzheimer pueden estar ligados al daño ocasionado por una reacción extrema de radicales libres (Amié et al., 2003; Rodríguez et al., 2001). Los radicales libres también son generados por diversos contaminantes, por radiaciones solares y por algunos medicamentos.

Muchos compuestos químicos tienen la capacidad de inhibir a los radicales libres en el organismo o impedir su formación y se les conoce como compuestos antioxidantes, que por definición son sustancias que estando presentes a baja concentración con respecto a una molécula oxidable (biomolécula), retarda o previene la oxidación de este sustrato (García et al., 2001).
Los antioxidantes reaccionan con los radicales libres para formar compuestos estables no reactivos, proceso conocido como "atrapamiento (captura) de radicales libres". En la industria alimenticia y farmacéutica se utilizan antioxidantes sintéticos como el ácido ascórbico, el butilhidroxitolueno (BHT) y butilhidroxianisol (BHA), estos últimos de tipo fenólico y de los cuales se ha cuestionado su uso por implicaciones de tipo tóxico y cancerígeno (Maestro y Borja, 1993).

Existen abundantes fuentes de antioxidantes en diversos tipos de plantas, vegetales, frutas, hojas, cereales, plantas herbáceas, raíces y cortezas (Kahkonen et al., 1999; Yang et al., 2001). En la mayoría de ellos los compuestos que le imparten la propiedad antioxidante son los fenoles, en diversas formas, fenoles simples, flavonoides y/o taninos (Pérez, 2003; Maestro y Borja, 1993; Hagerman et al., 1998), debido a sus propiedades redox, lo cual les permite actuar como agentes reductores donadores de hidrógeno y estabilizadores de oxígeno reactivo, además de tener excelentes propiedades de quelación de hierro y otros metales de transición. Sus propiedades antirradicales libres se dirigen fundamentalmente hacia los radicales hidroxilo y superóxido implicados en el inicio de la cadena de peroxidación lipídica (Martínez et al., 2002; Amié et al., 2003).

Se han reportado especies maderables como fuente de compuestos fenólicos, tales como agujas de coníferas, corteza de abedul (Kahkonen et al., 1999) y el extracto de Pinus maritima (Pycnogenol), que probablemente es el extracto de corteza más estudiado, con una excelente capacidad de captura de radicales libres (Packer et al., 1999; Virgili et al., 2000).

Diversas investigaciones indican que además de las propiedades antioxidantes de los fenoles, poseen propiedades antibacterianas, antivirales y anti- 
fúngicas (De Bruyne et al., 1999; Ramachandra y Ravishankar, 2002; Scalbert, 1991).

Con anterioridad se reportó que las cortezas de algunas especies de pino representativas del estado de Durango tienen una alta concentración de compuestos fenólicos (Rosales y González, 2003), y que dada la abundancia del recurso representan una fuente potencial para una posible utilización en áreas biológicas. En el presente trabajo se presenta una evaluación de dos parámetros que pueden ayudar a conocer aun más sobre el potencial que puedan tener los extractos de corteza de pino en áreas biomédicas.

\section{OBJETIVO}

Evaluar la capacidad de captura de antirradicales libres y antibacteriana de extractos etanólicos y acuosos de las cortezas de cinco especies de pino.

\section{METODOLOGÍA}

Las especies estudiadas fueron $P$. ayacahuite, P. cooperi, P. durangensis, $P$. leiophylla y $P$. teocote, recolectadas en el municipio de Pueblo Nuevo, Durango. Se depositaron ejemplares botánicos en el Herbario del CIIDIR IPN Unidad Durango con los números 18939, 22531, 18938, 22527 y 18795, respectivamente. Se obtuvieron extractos en etanol acuoso al 50,0\% por maceración a temperatura ambiente durante $24 \mathrm{~h}$, adicionando $100 \mathrm{~mL}$ del solvente a $10 \mathrm{~g}$ de corteza. El extracto resultante se filtró sobre papel filtro y a la corteza remanente se le adicionaron $100 \mathrm{~mL}$ de solvente fresco y se repitió el proceso. Los extractos se combinaron y el solvente se evaporó en un rotavapor a $35{ }^{\circ} \mathrm{C}$ aplicando vacío (Rosales y González, 2003).
El extracto resultante se secó por liofilización. Los extractos acuosos se obtuvieron adicionando $200 \mathrm{~mL}$ de agua a $20 \mathrm{~g}$ de corteza, se calentó a ebullición y reflujo durante $1 \mathrm{~h}$. Los extractos se filtraron mediante papel filtro y se secaron por liofilización.

\section{Evaluación de la capacidad de captura de radicales libres}

La capacidad de atrapar radicales libres se evaluó por el método del DPPH, un método espectrofotométrico en el que se utiliza el radical libre estable 1,1-difenil-2picrilhidracilo (DPPH), que tiene un fuerte color violeta y una intensa banda de absorción a $515 \mathrm{~nm}$. Cuando una solución de DPPH se mezcla con una sustancia que puede donar átomos de hidrógeno, capaz de estabilizarlo, el color violeta intenso decae, con la consecuente disminución de la absorbancia (Molyneux, 2004).

Para esta evaluación, los extractos etanólicos y acuosos liofilizados se disolvieron en etanol acuoso al 50,0\%. Se ensayaron cinco concentraciones de extracto $(250,500,750,1000$ y 1250$) \mathrm{mg}$ $\mathrm{L}^{-1}$. Como parámetros de referencia se utilizaron los estándares comerciales butilhydroxitolueno (BHT) y butilhydroxianisol (BHA), a las mismas concentraciones de prueba de los extractos. A $40 \mu \mathrm{L}$ del extracto o estándar se le adicionaron 3 $\mathrm{mL}$ de solución $1 \times 10^{-3} \mathrm{M}$ del radical DPPH. La mezcla se agitó y después de 30 minutos de la adición del radical se leyó la absorbancia a $515 \mathrm{~nm}$. Para medir la absorbancia inicial se utilizaron $40 \mu \mathrm{L}$ de etanol al 50,0\% en lugar del extracto $\left(A_{0}\right)$. Se realizaron tres repeticiones para cada concentración de extracto y estándar. La capacidad de atrapar radicales libres (ARL), llamada también inhibición de radicales libres se calculó de acuerdo con la fórmula (1) (Sánchez-Moreno et al., 1998; Molyneux, 2004). 
(1) $\quad A R L=100\left(A_{0}-A_{m}\right) / A_{0}$

donde:

$A_{0}=$ Absorbancia inicial del radical DPPH sin muestra

$A_{m}=$ Absorbancia de la solución con muestra (DPPH + extracto)

\section{Evaluación de la actividad antibacteriana}

Para la evaluación antibacteriana se utilizó el método de dilución en agar. Los microorganismos de prueba fueron Staphylococcus aureus (ATCC 25923), Enterococcus sp., Escherichia coli (ATCC 25922) y Pseudomonas aeruginosa (ATCC 27853). Se probaron cinco concentraciones de extracto $(0,625,2,5,5,0,10,0$ y $20,0) \mathrm{mg} / \mathrm{mL}$. El inóculo se preparó a una densidad aproximada de $10^{8}$ unidades formadoras de colonias (UFC), comparando la turbidez con el estándar 0,5 de MacFarland. Se prepararon cajas Petri con $25 \mathrm{~mL}$ de medio de cultivo Müller Milton, en el cual estaban disueltos los extractos a las diferentes concentraciones. Las bacterias se sembraron sobre las cajas mediante un asa bacteriológica calibrada de $0,001 \mathrm{~mL}$ y se incubaron a $35{ }^{\circ} \mathrm{C}$ durante $18 \mathrm{~h}$. Después de este tiempo se observó el crecimiento y/o la inhibición de las bacterias, codificándose como positivo (+) cuando hubo crecimiento de bacterias sobre las cajas y negativo (-) cuando no hubo crecimiento. Como control positivo se utilizó ampicilina a $0,008 \mathrm{mg} / \mathrm{mL}$ y como control negativo se utilizó agar sin extracto. Las pruebas se realizaron por duplicado y en algunos casos cuando no se tuvieron resultados reproducibles se probó por triplicado. Los resultados fueron expresados como Concentración Mínima Inhibitoria (CMI) que indica la concentración mínima de extracto que impide el crecimiento de una cepa bacteriana (Mendoza, 2002; Koneman, 2001; Vander, 1989).

\section{Diseño experimental}

Para evaluar las diferencias estadísticas en el atrapamiento de radicales libres se trabajó con un arreglo factorial, con tres repeticiones, considerando como factores las especies (cinco especies más dos estándares) y los tratamientos (etanólico y acuoso).

\section{RESULTADOS Y DISCUSIÓN}

Los resultados promedio de tres repeticiones de la capacidad de captura de radicales libres y su desviación estándar se presentan en las tablas 1 y 2 . El comportamiento desarrollado por los extractos de las diferentes especies a las concentraciones probadas se presenta en las figuras 1 a 5 .

Tabla 1. Porcentaje promedio y desviación estándar de la capacidad de captura de radicales libres de los extractos etanólicos

\begin{tabular}{lccccc}
\hline & \multicolumn{5}{c}{ CONCENTRACIÓN EN MG L-1 } \\
Especie & 250 & 500 & 750 & 1000 & 1250 \\
\hline$P$. ayacahuite & $29,3 \pm 1,11$ & $56,4 \pm 0,35$ & $80,4 \pm 0,26$ & $91,7 \pm 0,43$ & $92,7 \pm 0,36$ \\
P. cooperi & $25,4 \pm 0,81$ & $50,0 \pm 0,72$ & $68,5 \pm 0,79$ & $81,8 \pm 0,62$ & $87,9 \pm 0,75$ \\
P. durangensis & $50,1 \pm 1,44$ & $83,0 \pm 1,41$ & $89,1 \pm 0,26$ & $89,2 \pm 0,28$ & $90,9 \pm 0,62$ \\
P. leiophylla & $54,1 \pm 1.41$ & $90.4 \pm 0,98$ & $92,0 \pm 0,10$ & $92,0 \pm 0,17$ & $92,0 \pm 0,06$ \\
P. teocote & $40,4 \pm 1,05$ & $72,8 \pm 0,87$ & $91,4 \pm 0,45$ & $91,8 \pm 0,26$ & $92,0 \pm 0,10$ \\
BHT & $28,6 \pm 0,82$ & $50,3 \pm 0,72$ & $63,4 \pm 1,05$ & $70,9 \pm 0,70$ & $78,0 \pm 0,43$ \\
BHA & $57,0 \pm 0,62$ & $83,6 \pm 0,20$ & $89,9 \pm 0,26$ & $91,2 \pm 0,45$ & $91,2 \pm 0,60$ \\
\hline
\end{tabular}




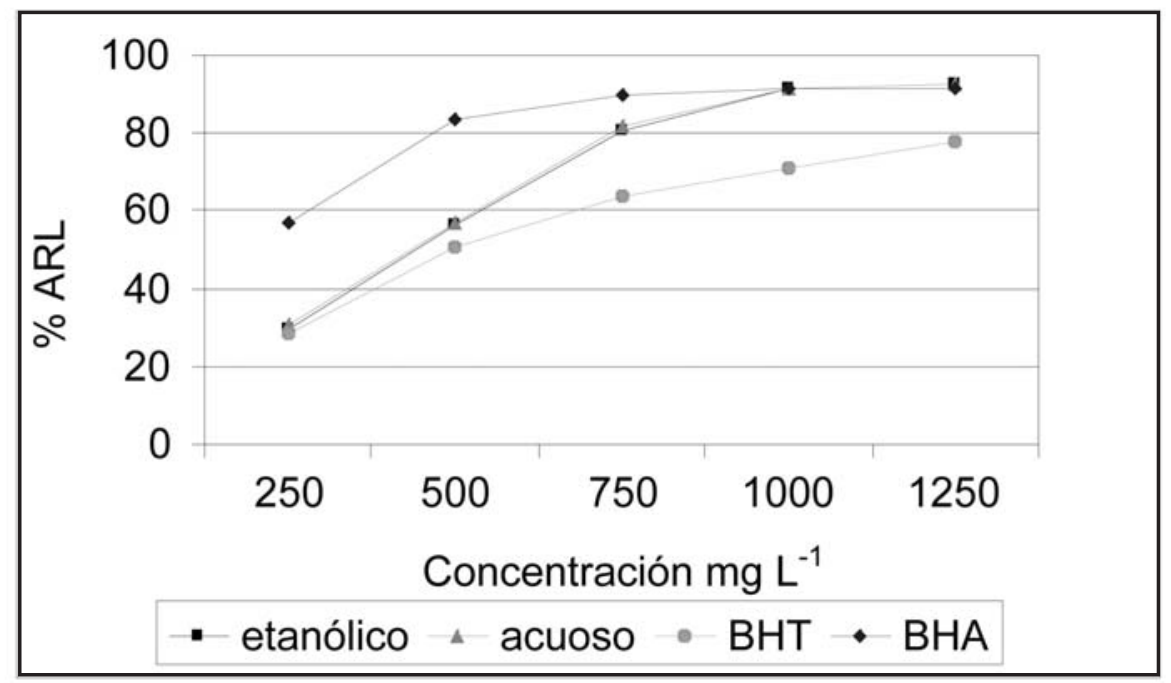

Figura 1. Captura de radicales libres de los extractos de $P$. ayacahuite



Figura 2. Captura de radicales libres de los extractos de $P$. cooperi 


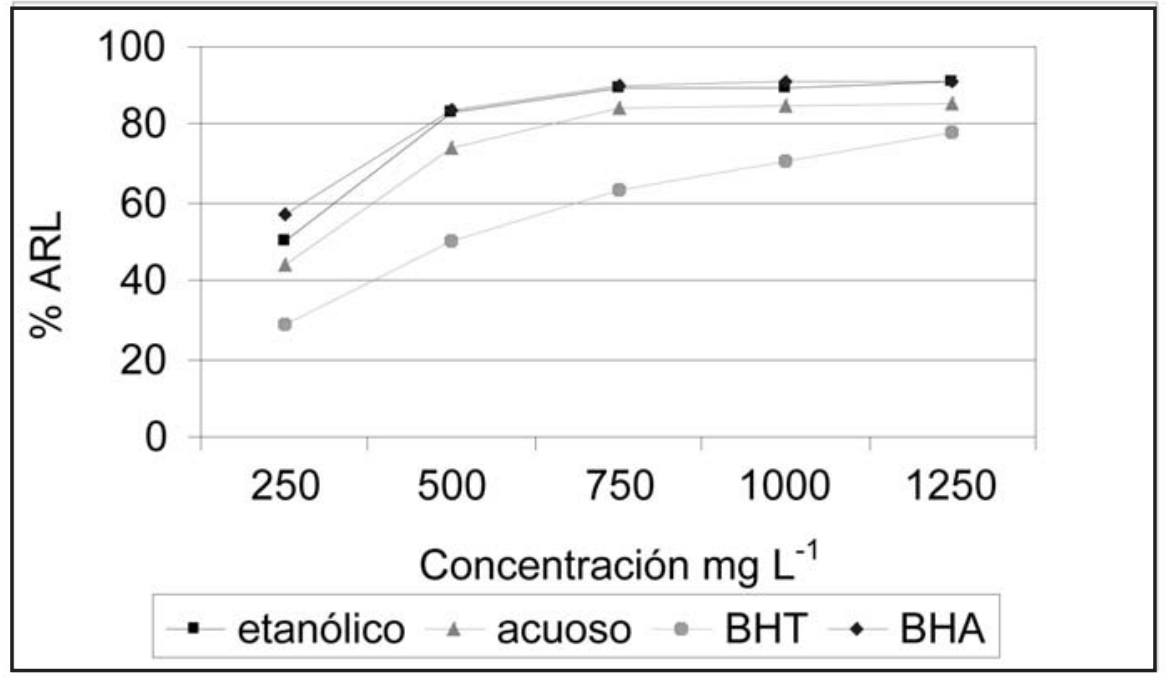

Figura 3. Captura de radicales libres de los extractos de $P$. durangensis

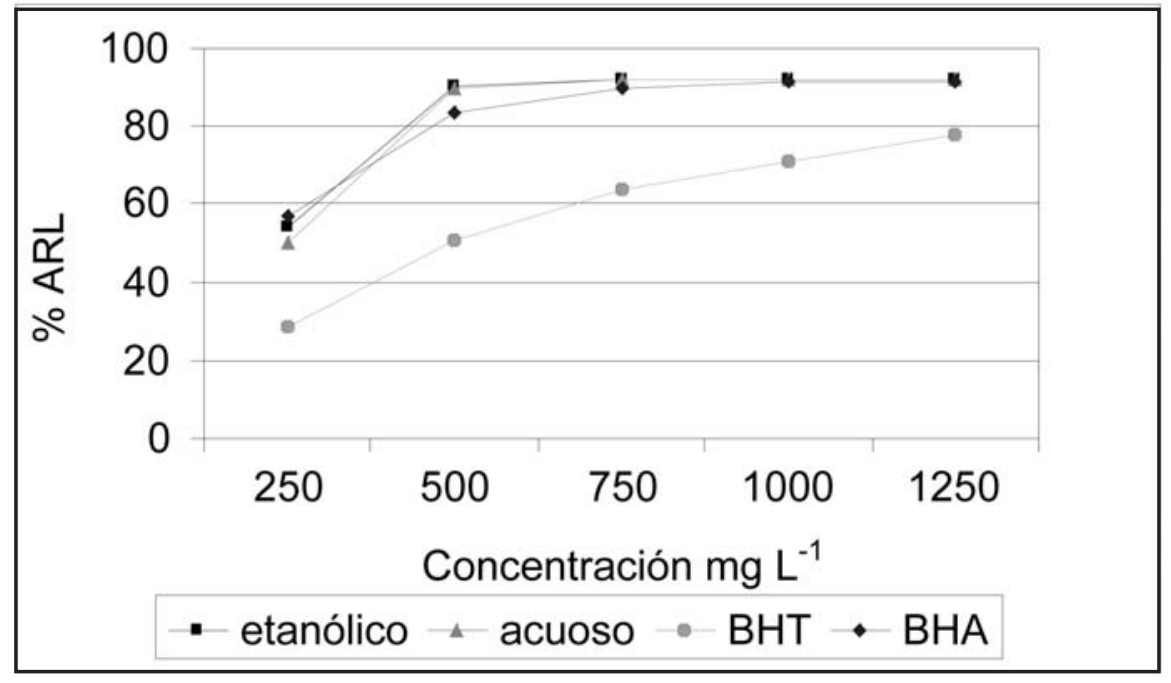

Figura 4. Captura de radicales libres de los extractos de $P$. leiophylla 


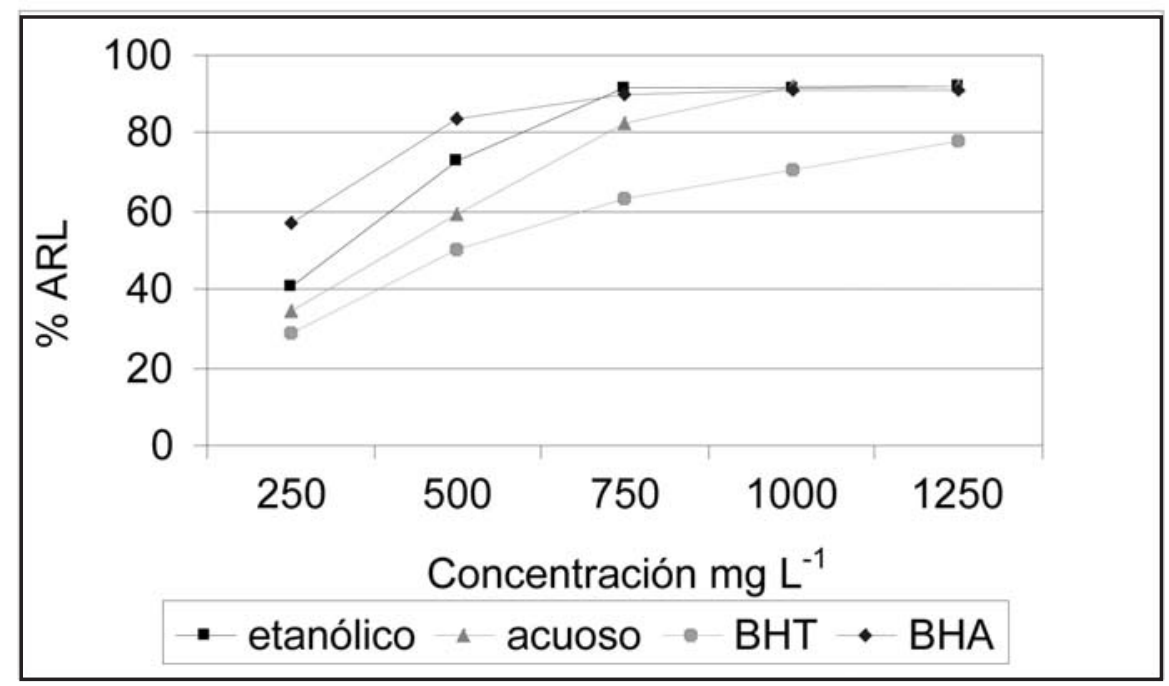

Figura 5. Captura de radicales libres de los extractos de $P$. teocote

Tabla 2. Porcentaje promedio y desviación estándar de la captura de radicales libres de los extractos acuosos

\begin{tabular}{lccccc}
\hline & & \multicolumn{4}{c}{ CONCENTRACIÓN EN MG L-1 } \\
Especie & 250 & 500 & 750 & 1000 & 1250 \\
\hline$P$. ayacahuite & $30,7 \pm 1,30$ & $56,7 \pm 0,72$ & $82,0 \pm 1,22$ & $91,6 \pm 0,55$ & $92,8 \pm 0,36$ \\
$P$. cooperi & $19,7 \pm 0,79$ & $35,7 \pm 0,82$ & $51,7 \pm 0,75$ & $65,0 \pm 0,75$ & $75,2 \pm 0,26$ \\
$P$. durangensis & $44,3 \pm 1,08$ & $74,0 \pm 1,01$ & $84,4 \pm 0,62$ & $85,0 \pm 0,10$ & $85,2 \pm 0,52$ \\
P. leiophylla & $50,0 \pm 0,45$ & $89,7 \pm 0,72$ & $92,0 \pm 0,20$ & $92,0 \pm 0,10$ & $92,1 \pm 0,05$ \\
P. teocote & $34,7 \pm 0,70$ & $59,2 \pm 0,26$ & $82,3 \pm 0,55$ & $92,0 \pm 0,05$ & $92,0 \pm 0,05$ \\
BHT & $28,6 \pm 0,82$ & $50,3 \pm 0,72$ & $63,4 \pm 1,05$ & $70,9 \pm 0,70$ & $78,0 \pm 0,43$ \\
BHA & $57,0 \pm 0,62$ & $83,6 \pm 0,20$ & $89,9 \pm 0,26$ & $91,2 \pm 0,45$ & $91,2 \pm 0,60$ \\
& & & & & \\
\hline
\end{tabular}

Excepto el extracto acuoso de $P$. cooperi, a una concentración de $500 \mathrm{mg}$ $\mathrm{L}^{-1}$, todos los extractos, tanto etanólicos como acuosos tienen un $50,0 \%$ o más de captura del radical. En extractos etanólicos a esta concentración, no se encontraron diferencias estadísticas $(p>0,05)$ de la captura entre el extracto de $P$. durangensis $(83,0 \%)$ y BHA $(83,6 \%)$, ni entre el extracto de $P$. cooperi $(50,0 \%)$ con respecto a $\mathrm{BHT}(50,3 \%)$. En extractos acuosos todos los valores de captura fueron estadísticamente diferentes $(p \leq 0,05)$ (Tabla 3). 
A $750 \mathrm{mg} \mathrm{L}^{-1} P$. leiophylla alcanza el valor máximo de captura de $92,0 \%$, en ambos extractos, y no presenta diferencias estadísticas con el extracto etanólico de P. teocote (Tabla 4). Tampoco se encontraron diferencias estadísticas entre $P$. durangensis y BHA. En el extracto acuoso, $P$. teocote y $P$. ayacahuite no mostraron diferencia significativa, con capturas de $82,3 \%$ y $82,0 \%$.

A una concentración de 1250 mg L-1, que fue la máxima concentración probada, tanto los extractos etanólicos como acuosos de $P$. ayacahuite, $P$. teocote y $P$. leiophylla no tuvieron diferencias estadísticas $(p>0,05)$ en el porcentaje de captura, con porcentajes de $(92,7$ y 92,8$) \%$, (92,0 y 92,0$) \%$ y $(91,9$ y 92,0$) \%$, respectivamente (Tabla 5). A excepción del extracto acuoso de $P$. cooperi, todos los extractos presentaron mayor captura del radical que el alcanzado por el antioxidante comercial $\mathrm{BHT}$, que tuvo un porcentaje máximo de $78,0 \%$.

Las especies $P$. ayacahuite y $P$. leiophylla tuvieron el mismo porcentaje de captura en el extracto etanólico y acuoso (figuras 1 y 4), mientras que en $P$. cooperi se presenta una diferencia del 15,0\% entre el extracto etanólico y el acuoso (Fig. 2).

Tabla 3. Tabla de medias del porcentaje de captura de radicales libres, a $500 \mathrm{mg} \mathrm{L}^{-1}$

\begin{tabular}{lcll}
\hline & \multirow{2}{*}{ EXTRACTO ETANÓlico } & \multicolumn{2}{c}{ EXTRACTO ACUOSO } \\
\hline Especie & Media ${ }^{*}$ & Especie & Media \\
\hline P. leiophylla & $90,4 \mathrm{a}$ & P. leiophylla & $89,7 \mathrm{a}$ \\
BHA & $83,6 \mathrm{~b}$ & BHA & $83,6 \mathrm{~b}$ \\
P. durangensis & $83,0 \mathrm{~b}$ & P. durangensis & $74,0 \mathrm{c}$ \\
P. teocote & $72,8 \mathrm{c}$ & P. teocote & $59,2 \mathrm{~d}$ \\
P. ayacahuite & $56,4 \mathrm{~d}$ & P. ayacahuite & $56,7 \mathrm{e}$ \\
BHT & $50,3 \mathrm{e}$ & BHT & $50,3 \mathrm{f}$ \\
P. cooperi & $50,0 \mathrm{e}$ & P. cooperi & $35,7 \mathrm{~g}$ \\
\hline
\end{tabular}

* Valores con literales distintas en una hilera son estadísticamente diferentes $(p \leq 0,05)$.

Tabla 4. Tabla de medias del porcentaje de captura de radicales libres, a $750 \mathrm{mg} \mathrm{L-1}$

\begin{tabular}{llll}
\hline \multicolumn{3}{c}{ EXTRACTO ETANÓLICO } & \multicolumn{2}{c}{ EXTRACTO ACUOSO } \\
\hline Especie & Media * & Especie & Media \\
\hline P. leiophylla & $92,0 \mathrm{a}$ & P. leiophylla & $92,0 \mathrm{a}$ \\
P. teocote & $91,4 \mathrm{a}$ & BHA & $89,9 \mathrm{~b}$ \\
BHA & $89,9 \mathrm{~b}$ & P. durangensis & $84,4 \mathrm{c}$ \\
$P$. durangensis & $89,1 \mathrm{~b}$ & P. teocote & $82,3 \mathrm{~d}$ \\
$P$. ayacahuite & $80,4 \mathrm{c}$ & P. ayacahuite & $82,0 \mathrm{~d}$ \\
$P$. cooperi & $68,5 \mathrm{~d}$ & BHT & $63,4 \mathrm{e}$ \\
BHT & $63,4 \mathrm{e}$ & P. cooperi & $51,7 \mathrm{f}$ \\
& & & \\
\hline
\end{tabular}

* Valores con literales distintas en una hilera son estadísticamente diferentes $(p \leq 0,05)$. 
Tabla 5. Tabla de medias del porcentaje de captura de radicales libres, a $1250 \mathrm{mg} \mathrm{L}^{-1}$

\begin{tabular}{lcll}
\hline & \multirow{2}{*}{ EXTRACTO ETANÓlico } & \multicolumn{2}{c}{ EXTRACTO ACUOSO } \\
\hline Especie & Media * & Especie & Media \\
\hline P. ayacahuite & $92,7 \mathrm{a}$ & P. ayacahuite & $92,8 \mathrm{a}$ \\
P. teocote & $92,0 \mathrm{ab}$ & P. leiophylla & $92,0 \mathrm{ab}$ \\
P. leiophylla & $91,9 \mathrm{~b}$ & P. teocote & $92,1 \mathrm{~b}$ \\
BHA & $91,2 \mathrm{c}$ & BHA & $91,2 \mathrm{c}$ \\
P. durangensis & $90,9 \mathrm{c}$ & P. durangensis & $85,2 \mathrm{~d}$ \\
P. cooperi & $87,9 \mathrm{~d}$ & BHT & $78,0 \mathrm{e}$ \\
BHT & $78,0 \mathrm{e}$ & $P$. cooperi & $75,2 \mathrm{f}$ \\
\end{tabular}

* Valores con literales distintas en una hilera son estadísticamente diferentes $(p \leq 0,05)$.

Otra forma de comparar la eficiencia de la captura de radicales libres de los diferentes extractos es mediante el cálculo de la concentración a la cual los extractos atrapan o inhiben el $50,0 \%$ de los radicales. Esta medida se conoce como "la concentración eficiente 50,0\%", y se abrevia $\mathrm{CE}_{50}$, (Molyneux, 2004). Se realizó el cálculo de esta medida para cada uno de los extractos probados, utilizando regresión lineal, los resultados se muestran en la figura 6 . De acuerdo con esta medida, la especie que tiene la mejor $\mathrm{CE}_{50}$ es $P$. leiophylla con (231 y 250) $\mathrm{mg} \mathrm{L}^{-1}$ en extracto etanólico y acuoso, respectivamente y el $P$. cooperi es el que tiene la menor eficiencia, con $\mathrm{CE}_{50}$, (500 y 723) $\mathrm{mg} \mathrm{L}^{-1}$.

Para el extracto de Pinus maritima (Pycnogenol), se registra una $\mathrm{CE}_{50}$ de 90,0 mg L-1, (Raimo, 2005). Bajo este marco de referencia, este extracto es más eficiente que los extractos y estándares evaluados en este trabajo. Sin embargo, no se identifica la tendencia antirradical de este extracto a otras concentraciones.
Con respecto a la actividad antibacteriana, los extractos etanólicos mostraron mayor actividad que los acuosos (Tabla 6). Las bacterias grampositivas (Staphylococcus aureus y Enterococcus sp.) mostraron mayor susceptibilidad a ser inhibidas por los extractos que las bacterias gram-negativas (Escherichia coli y Pseudomonas aeruginosa). S. aureus mostró muy buena inhibición por los extractos etanólicos de todas las especies (CMI 0,625 mg/mL) (Fig. 7), mientras que los extractos acuosos la inhibieron a $2,5 \mathrm{mg} / \mathrm{mL}$ y $5,0 \mathrm{mg} / \mathrm{mL}$ (Fig. 8). Enterococcus sp. fue inhibida a concentración de $2,5 \mathrm{mg} / \mathrm{mL}$ o menor por el $80,0 \%$ de los extractos. La inhibición para Escherichia coli fue a concentraciones de extracto de $10,0 \mathrm{mg} / \mathrm{mL}$ o mayor. Esta fue la bacteria que menos se inhibió por efecto de los extractos. Pseudomonas aeruginosa se inhibió a 2,5 $\mathrm{mg} / \mathrm{mL}$ por el extracto etanólico de $P$. cooperi, a $5,0 \mathrm{mg} / \mathrm{mL}$ por los dos extractos de $P$. durangensis y a concentraciones mayores para el resto de los extractos. 


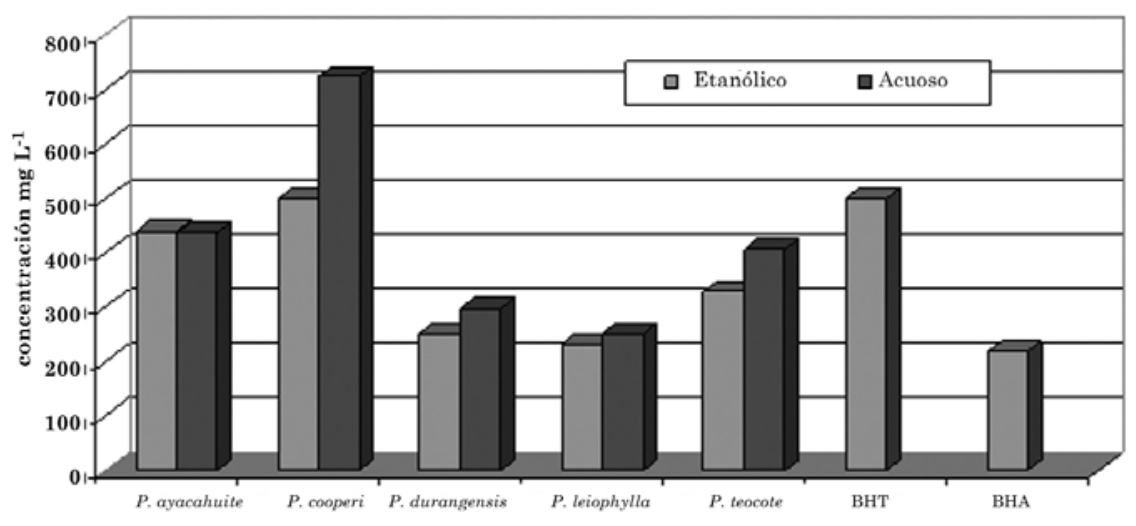

Figura 6. Concentración de extracto para inhibir el 50,0 \% de los radicales libres

Tabla 6. Actividad antibacteriana de extractos etanólicos y acuosos

\begin{tabular}{lcccc}
\hline ESPECIE & \multicolumn{4}{c}{ CONCENTRACIÓN MíNIMA INHIBITORIA CMI (mg/mL) } \\
\hline \hline EXTRACTOS ETANÓLICOS & S. aureus & E. sp. & E. coli & P. aeruginosa \\
\hline$P$. ayacahuite & 0,625 & 0,625 & 10,0 & 10,0 \\
$P$. cooperi & 0,625 & 2,5 & 10,0 & 2,5 \\
$P$. durangensis & 0,625 & 2,5 & 10,0 & 5,0 \\
$P$. leiophylla & 0,625 & 2,5 & 20,0 & 5,0 \\
$P$. teocote & 0,625 & 2,5 & 20,0 & 20,0 \\
\hline EXTRACTOS Acuosos & & & & 10,0 \\
& & & & 20,0 \\
$P$. ayacahuite & 2,5 & 2,5 & 20,0 & 5,0 \\
$P$. cooperi & 5,0 & 20,0 & 20,0 & 10,0 \\
$P$. durangensis & 2,5 & 2,5 & 10,0 & 20,0 \\
$P$. leiophylla & 2,5 & 2,5 & 20,0 & 0,008 \\
$P$. teocote & 5,0 & 10,0 & 20,0 & \\
\hline & & & & \\
AMPICILINA & 0,008 & 0,008 & 0,008 & \\
\hline
\end{tabular}




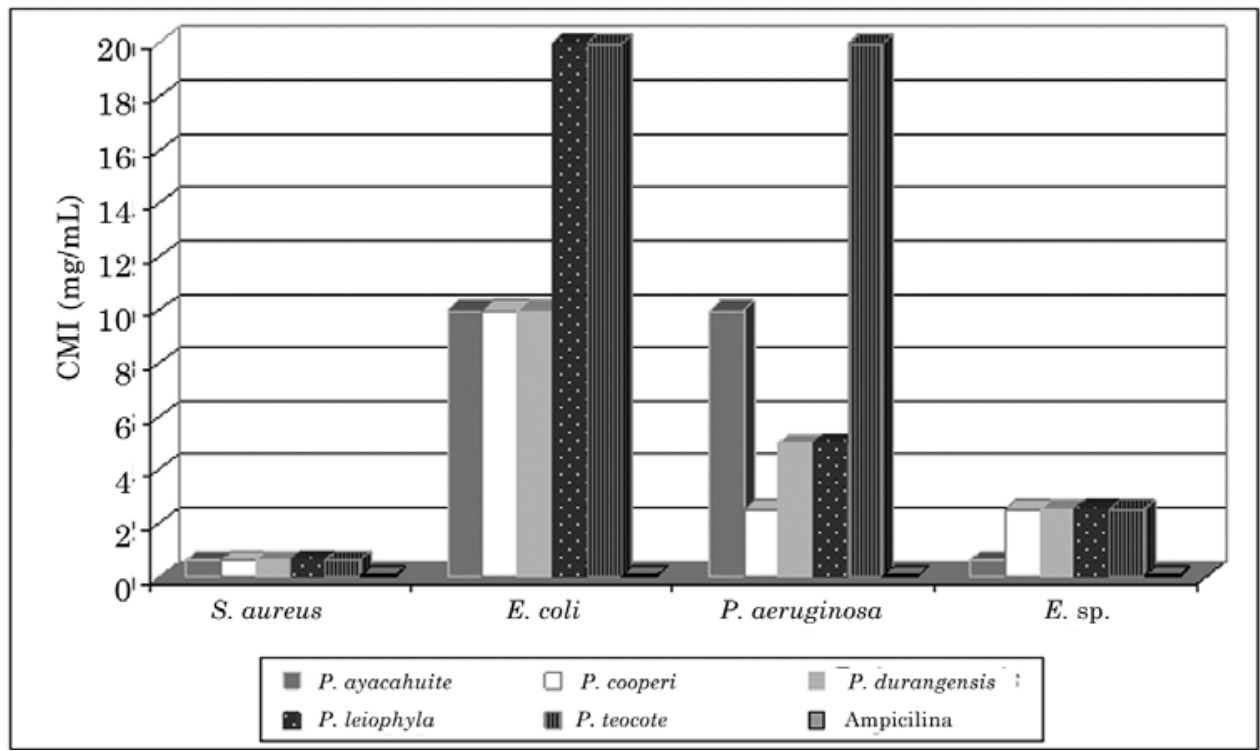

Figura 7. Concentración mínima inhibitoria de los extractos etanólicos sobre bacterias



Figura 8. Concentración mínima inhibitoria de los extractos acuosos sobre bacterias 
En los extractos de algunas especies, no existe una relación directa entre una eficiente actividad antirradical y una buena actividad antibacteriana, como es el caso de $P$. leiophylla, en la que sus extractos tienen alta eficiencia antirradical y muy baja inhibición sobre $E$. coli. Mientras que en el caso de $P$. cooperi, que es la especie que presentó las menores características de captura de radicales, el extracto etanólico de esta especie es el que presenta la mejor actividad contra $P$. aeruginosa, de la cual se ha encontrado ser resistente a muchos de los fármacos estándares (Mendoza, 2002), aunque también inhibe de forma eficiente al resto de las bacterias.

Los extractos acuosos de $P$. teocote y $P$. cooperi no tuvieron buena inhibición sobre las bacterias. Los resultados generales obtenidos en este trabajo indican que existen diferencias estadísticas $(p \leq 0,05)$ (tablas 3,4 y 5 ) en la actividad antirradical y antibacteriana entre especies, tipo de extracto y concentraciones aplicadas. Aunque estas evaluaciones se han realizado en extractos crudos, sin ningún tipo de purificación o separación cromatográfica, con anterioridad se encontró que la concentración de compuestos fenólicos en estos extractos crudos es alta (Rosales y González, 2003), por lo tanto se deduce que estos compuestos pudieran ser los responsables de dicha actividad y que la variabilidad encontrada pudiera deberse a características particulares de las estructuras fenólicas, tales como mayor o menor cantidad de grupos hidroxilo en la molécula, tipo de sustitución y posición en el anillo bencénico, formas monoméricas o polimerizadas, entre otras. Esto, debido a que están estrechamente relacionadas con las actividades antirradicales libres y antibacteriana que presenten (Amié et al., 2003; Yang, 2001).

\section{CONCLUSIONES}

Los extractos etanólicos de las especies estudiadas tienen altos niveles de actividad antirradical libre, sobresaliendo los obtenidos de las especies $P$. leiophylla y $P$. durangensis. Estos extractos tienen muy buena actividad sobre $S$. aureus y Enterococcus sp. El Pinus cooperi solo se presenta como un buen inhibidor de $P$. aeruginosa. Aunque los extractos acuosos de algunas de las cortezas estudiadas tienen una actividad menor, comparada con la que presentan los extractos etanólicos, se les puede considerar también como una fuente importante de compuestos antirradicales libres. Con la limitante que se requiere de una mayor dosis para alcanzar la actividad, pero con la ventaja de que estos extractos se obtienen por un método sencillo y económico. Los resultados obtenidos muestran que la corteza de pino podría tener alternativas de aprovechamiento desde el punto de vista farmacológico.

\section{REFERENCIAS}

Amié, D., D. Davidovie-Amié, D. Beslo y N. Trinajstic. 2003. Structure-radical scavenging activity relationships of flavonoids. Croatica Chemical Acta 76(1):55-61.

De Bruyne, T., L. Pieters, H. Deelstra y A. Vlietinck. 1999. Condensed vegetable tanins: Biodiversity in structure and biological activities. Biochemical Systematics and Ecology 27: 445459.

García, L., L. García, D. Rojo y E. Sánchez. 2001. Plantas con propiedades antioxidantes. Revista Cubana Investigaciones Biomédicas 20(3):231-235. 
González, C., M. Betancourt y R. Ortiz. 2000. Daño oxidativo y antioxidantes. Bioquimia 25(1):3-10.

Hagerman, A., K.M Riedl, A. Jones, K. Sovik, N. Ritchard, P.W. Hartzfeld y T.L. Riechel. 1998. High molecular weight plant polyphenolics (tannins) as biological antioxidants. J. Agric. Food Chem. 46(5):1887-1892.

Kahkonen, M.P., A.I. Hopia, H.J. Vuorela, J.P. Rauha, K. Pihlaja, T.S. Kujala y M. Heinonen. 1999. Antioxidant activity of plant extracts containing phenolic compounds. J. Agric. Food Chem. 47(10):3954-3962.

Koneman, E. 2001. Diagnóstico microbiológico. Panamericana, España, p. 790 .

Maestro D, R. y R. Borja. 1993. Actividad antioxidante de los compuestos fenólicos. Grasas y Aceites 44(2):101-106.

Martínez, S., J. González, J.M. Culebras y M.J. Tuñón. 2002. Los flavonoides: propiedades y acciones antioxidantes. Nutr. Hosp. 17(6): 271-278.
Mendoza, A.R. 2002. Antimicrobianos 2002. Instituto Politécnico Nacional, México, D. F. 176 p.

Molyneux, P. 2004. The use of the stable free radical diphenylpicryl-hydrazyl (DPPH) for estimating antioxidant activity. Songklanakarin J. Sci. Technol. 26(2):211-219.

Packer, L., G. Rimbach y F. Virgil. 1999. Antioxidant activity and biologic properties of a procyanidin-rich extract from Pine (Pinus maritima) bark, pycnogenol. Free Radical Biology \& Medicine 27(5,6):704-724.

Pérez T, G. 2003. Los flavonoides: antioxidantes o prooxidantes. Rev. Cubana Invest. Biomed. 22(1):48-57.

Raimo, H. 2005. Antioxidant and free radical scavenging activity testing methods. Department of Pharmacy, University of Helsinki. http:www.ics. trieste.it/documents. Octubre 18, 2005.

Ramachandra R, S. y G.A. Ravishankar. 2002. Plant cell cultures: Chemical factories of secondary metabolites. Biotechnology advances 20:101-153. 
